\title{
Patrimonio cultural inmaterial en las Reservas de la Biosfera cantábricas: la recuperación de la toponimia en los Valles de Omaña y Luna (León)*
}

\section{Cultural heritage in Cantabrian Biosphere Reserves: recovering Omana and Luna Valleys toponymy}

\author{
Alipio J. García de Celis ${ }^{1}$, Luis Carlos Martínez Fernández $z^{2}$ \\ e Ignacio Prieto Sarro ${ }^{3}$
}

\begin{abstract}
RESUMEN
La Reserva de la Biosfera de los Valles de Omaña y Luna (Cordillera Cantábrica, León, España) ha iniciado un procedimiento para recuperar y cartografiar el patrimonio toponímico extraordinariamente rico que cubre su territorio como una malla invisible, inmaterial. Se está llevando a cabo mediante un método participativo en el que se implica a la población local. Los resultados se elevan al Instituto Geográfico Nacional y quedan incorporados en la cartografía pública disponible a través del visor Iberpix-4. Es un ejemplo de metodología para la recuperación de la toponimia como parte del patrimonio cultural inmaterial.
\end{abstract}

Palabras clave: toponimia, reservas de la biosfera, patrimonio cultural inmaterial.

* Este estudio ha sido facilitado por la Reserva de la Biosfera, como parte de la Línea Estratégica 1 (Conservación del patrimonio natural y cultural. Acción: Recuperación del patrimonio cultural inmaterial), de su Plan Estratégico.

1 Facultad de Filosofía y Letras, Universidad de Valladolid alipio@fyl.uva.es ORCID iD: http://orcid.org/0000-0003-3314-3166

2 Facultad de Educación de Segovia, Universidad de Valladolid luiscar@fyl.uva.es ORCID iD: http://orcid.org/0000-0002-3116-1750

3 Servicio de Cartografía, Universidad de León ORCID iD: http://orcid.org/0000-0003-0049-2845

Copyright: (0) 2018 CSIC. Este es un artículo de acceso abierto distribuido bajo los términos de la licencia de uso y distribución Creative Commons Reconocimiento 4.0 Internacional (CC BY 4.0). 
Abstract

The Biosphere Reserve of the Omaña and Luna Valleys (part of the Great Cantabrian, Leon, Spain) has started a process of mapping and recovering the toponymic patrimony that extends throughout the territory like an invisible and immaterial mesh. This task is being carried out in a collaborative way with the implication of the local population. The results are passed on to the National Geographical Institute that subsequently incorporates them into the public cartography available through the Iberpix-4 visor. This is an example of a methodology that can be used to recover the toponyms of an area as part of the immaterial cultural patrimony.

KEY WORDs: toponymy, biosphere reserves, immaterial cultural patrimony.

Cómo citar este artículo/Citation: García de Celis, Alipio J., Martínez Fernández, Luis Carlos, Prieto Sarro, Ignacio (2018): "Patrimonio cultural inmaterial en las Reservas de la Biosfera cantábricas: la recuperación de la toponimia en los Valles de Omaña y Luna (León)", Estudios Geográficos, LXXIX/284, pp. 191-208

\section{INTRODUCCIÓN}

«La terca y minuciosa labor de campesinos y pastores, durante siglos, se resume en un corpus de prácticas y conocimientos, en gran parte borrado por la irrupción de saberes deslocalizados que se originan en las mallas de la ciencia y tecnología trasnacional. Una fracción de aquel corpus la componen los restos de la tradición, el legado etnográfico. Otra parte, no menos ruinosa, es el mapa de nombres que, sobrepuesto al territorio, espiritualiza los terrones y asperezas del suelo con sus fonemas heredados. El conjunto de nombres geográficos de un término municipal, su micro-toponimia total, puede leerse como un texto que representa una teoría del lugar, contada desde la vida y el trabajo de sus pobladores»

Pascual Riesco Chueca (2010: 7).

A partir del verano de 2015, la Reserva de la Biosfera Valles de Omaña y Luna (León) ha puesto en marcha una iniciativa para recuperar el patrimonio cultural inmaterial que constituye la abundantísima red de nombres que cubre todo el territorio. La toponimia, en estos espacios montañosos aprovechados tradicionalmente por usos agrarios y ganaderos, es como una invisible pero tupida malla cuyos nudos son palabras transmitidas de generación en generación a lo largo de siglos. El actual abandono ha dejado sin utilidad práctica esa malla de nombres y referencias, y el despoblamiento y envejecimiento hacen prever su inminente pérdida definitiva e irremediable. Hoy los topónimos quizá no tengan 
la utilidad que tenían para los pastores y campesinos hasta hace cincuenta años, pero siguen teniendo muchas otras: las que se derivan del valor de esas palabras como codificaciones de un conocimiento empírico atesorado durante siglos, las de su valor léxico, arqueológico e histórico en general, y las de su valor, en definitiva, como elementos de un patrimonio cultural extraordinario ${ }^{4}$.

Exponemos a continuación el planteamiento, el método utilizado y algunos de los resultados obtenidos en el intento recuperar y conservar este patrimonio.

\section{Características territoriales del ÁREA DE ESTUdio y PLANTEAMIENTO DEL PROBLema}

La Reserva de la Biosfera de los Valles de Omaña y Luna (figura 1) es un territorio de montaña media y alta, con elevada altitud media, fuertes pendientes, clima y vegetación de transición atlántico-mediterránea, suelos poco profundos y densa red de manantiales, arroyos y ríos.

Tradicionalmente fue un espacio de aprovechamiento ganadero y en menor medida agrícola, orientado a la subsistencia, organizado a partir de pequeños núcleos de población de 100 a 300 habitantes de media y con una extensión de entre 10 y $20 \mathrm{Km}^{2}$ de terreno —el denominado término concejil—alrededor de cada pueblo.

En torno al núcleo de población se ordenaban los usos desde el ámbito más cercano hacia lo más lejano: huertas, prados de siega y tierras de centeno (divididas en parcelas de titularidad privada) y pastos comunales, puertos y brañas (de titularidad pública: pertenecientes al común de los vecinos) destinados a los diferentes tipos de ganado 5 .

Tanto la rotación de los cultivos de secano (centeno) como el manejo de los ganados se organizaba comunalmente en cada pueblo, mediante un órgano - el concejo- que regulaba usos y aprovechamientos ajustándose a unas Ordenanzas seculares establecidas de común acuerdo entre los vecinos (plasmadas por escrito en muchos casos en el siglo XVIII, habiéndose conservado hasta nuestros días las de varios pueblos) ${ }^{6}$.

4 Desde la Geografía, el interés suscitado por la dimensión espacial de los nombres de lugar ha quedado puesta de manifiesto por, entre otros: Arroyo, 2010; Rosselló, 2010; Tort, 2001; 2003; 2010; 2012.

5 En el caso de Omaña, Cortizo et al. (1994) han realizado un detallado análisis de este modelo de uso del territorio y su decadencia a partir de los años 50; en el caso concreto de Murias de Paredes analizaron el caso de Villanueva de Omaña.

6 Rubio (1993) ha realizado un detallado trabajo sobre las Ordenanzas leonesas, en un trabajo que incluye una transcripción de las correspondientes a tres localidades de Murias de 
FIGURA 1

MAPA DE SITUACIÓN. EN EL RECUADRO, EL ÁREA DE TRABAJO EN LA QUE SE EJEMPLIFICA LA RECUPERACIÓN TOPONÍMICA: EL ENTORNO DE LA LOCALIDAD DE VEGAPUJÍN (ver figuras 2 A 4)

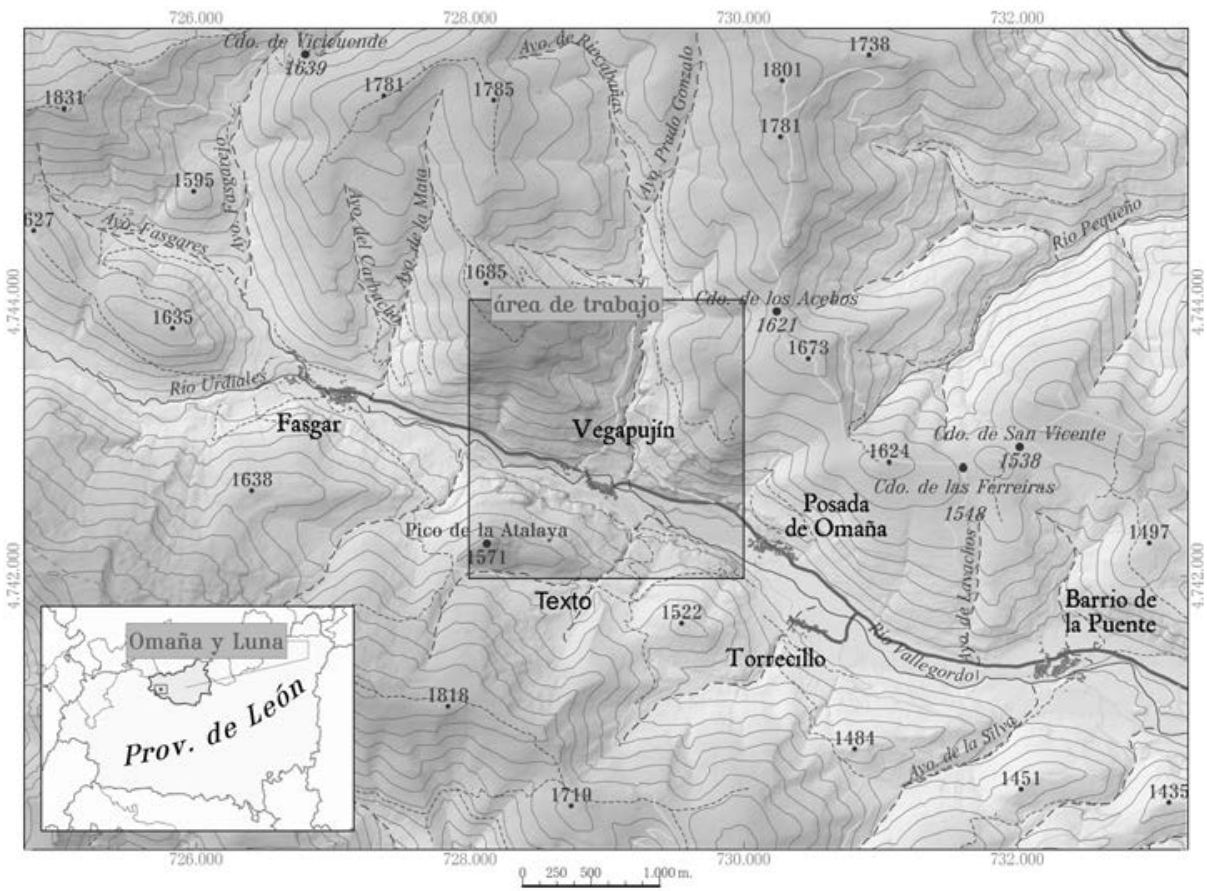

Los ganados de todos los vecinos se juntaban a diario en veceras (una para cada tipo de ganado) custodiadas por turnos por los propios vecinos ${ }^{7}$. Cada vecera realizaba unos recorridos de pastoreo perfectamente establecidos y regulados, diaria o estacionalmente, con base en una experiencia de siglos de funcionamiento.

Una organización comunitaria de un territorio tan extenso y orográficamente complicado exigía un perfecto conocimiento del medio y una localización e

Paredes: Fasgar (1757), Lazado (1762), Montrondo (1785). En el mismo sentido, Pérez (1998) es autora de un trabajo sobre el sistema concejil omañés en el cual, amén de las ordenanzas de las ya citadas localidades, se transcriben las de Posada, Torrecillo y Vegapujín (1751) y las de Senra (1786).

7 Sobre el término vecera, su uso en León y las limitaciones de la definición académica, puede consultarse a Le Men Moyer (1996: 1931-4). Gancedo (2013: 215, 321) recoge —en patsuezu- los términos veceira y veceirada. 
identificación exacta de cada rincón y cada lugar, lo que implicaba una rica toponimia que cubría exhaustivamente toda la superficie del término concejil.

Los vecinos adquirían el conocimiento de estas destrezas mediante su participación en el cuidado de las veceras de ganado desde la infancia, realizando a diario unos recorridos en los que iban memorizando los nombres de cada lugar mediante la transmisión oral de los mayores hacia los pequeños, al tiempo que adquirían las habilidades necesarias para el manejo del ganado, y aprendían los itinerarios, paradas, ritmos, horarios, etc. que exigía cada tipo de vecera.

Junto a la complicada jerga, hoy en desuso, relacionada con la ganadería ${ }^{8}$, un ingrediente fundamental en toda regulación descrita es el acervo toponímico que permite la referenciación espacial de la misma:

«...y se entiende que los sitios de donde pueden traerlas son desde el lugar hasta reguera luengo y en curuezas desde que se sale del lugar hasta el remate de la rodera que va al justo Fernando $[. . . / \ldots]$ por el camino arriba y abajo ni el saleras del lugar ni en otra ninguno ni bajarlas por la reguera del manzanal abajo [.../...] en todos los valles de buzquemado y el molar» (Ordenanzas de Montrondo, 1785. Art. 9).

La transmisión práctica y oral de estos conocimientos, de generación en generación, hacía que fuesen evolucionando, lo que podía significar el cambio en la forma de pronunciar algunas palabras, o incluso su sustitución en algunos casos, probablemente, pero también es lógico suponer que con la mayoría de ellos se han conservado nombres muy antiguos, que relacionan ciertos lugares con usos, hechos, construcciones, animales o plantas desaparecidos. Ello otorga a la toponimia, aparte del interés filológico, arqueológico o antropológico, un interés extraordinario en la reconstrucción de la historia del paisaje (Gordón, 2011; Prada, 2004; Prada et al., 2013).

En cualquier caso, todo ello constituía un acervo, una cultura, una ciencia local, destilada a través de un ejercicio de siglos, orientada a la excelencia en el aprovechamiento de los recursos locales.

El ordenamiento y gestión que acabamos de describir deja de funcionar entre los años 50 y 70 del siglo XX. La integración de estos territorios en la economía industrial contemporánea significa una transformación radical en los tipos de ganado y en su aprovechamiento, y un abandono absoluto de los usos agrícolas.

La población emigra en busca de trabajos en las ciudades, y los vecinos que se quedan transforman sus explotaciones: del modelo de subsistencia anterior se pasa rápidamente a una ganadería de orientación comercial, en una primera fase hacia el vacuno de leche estabulado (años 70-90), y en una segunda fase

8 Hablan las ordenanzas, por ejemplo, de jatos moseos (terneros de un año), de «echar al contario» (aparear ganados caballar y asnal para obtener ganado mular), etcétera. 
hacia el vacuno de carne en régimen extensivo (desde los años 90 hasta la actualidad).

Tanto uno como otro tipo de ganado ya no requiere el manejo anterior, y el aprovechamiento del medio ya no es exhaustivo. Resultado: el abandono de gran parte del territorio, que pasa a ser reocupado por la vegetación natural, matorrales en una primera fase, y bosques en una siguiente, proceso de regeneración que está en pleno desarrollo en la presente primera década y media del siglo XXI.

La consecuencia de todo lo anterior es la caída en desuso de la toponimia, pues ya no es necesario el manejo cotidiano de la totalidad del territorio entre diferentes vecinos, y ya no hay niños ni jóvenes que necesiten aprenderlo. Otra consecuencia es la desaparición y caída en el olvido de los recorridos de las veceras. Tales conocimientos ya sólo reposan en la memoria de las personas que vivieron ese sistema, hoy ya con más de sesenta o setenta años de edad.

En el caso de los topónimos es urgente - habida cuenta de dicha avanzada edad de la mayoría de los potenciales informantes- rescatar esos conocimientos, y organizarlos de alguna manera o en algún tipo de documento que garantice que no se pierdan y pasen a engrosar el listado de lo que Riesco (2010: 22) ha denominado «topónimos fantasmales»?.

Siendo inevitable que, al menos en el contexto actual de abandono generalizado de los espacios rurales, se interrumpa la dinámica de creación, sustitución o modificación de topónimos en función de las realidades cambiantes de los parajes (sustitución de cultivos, hechos notables acaecidos en los mismos, etcétera), conviene habilitar, al menos, un registro que haga las veces de inventario toponímico y que, en la medida de lo posible, arroje luz sobre su relación con un espacio concreto.

\section{UN MÉTODO PARA LA RECUPERACIÓN DE LA MEMORIA DEL TERRITORIO}

Ante la constatación de la urgencia antes mencionada, desde La Reserva de la Biosfera de los Valles de Omaña y Luna se pone en marcha en el verano

9 Ya a mediados del siglo pasado, Rubio (1956: 256) se percató de la rapidez de estos procesos, entonces incipientes, de pérdida de identidad cultural: «Creemos oportuno señalar que el material del presente vocabulario fue recogido en los años 1940-1945. Si este trabajo se hubiera realizado a principios del siglo, tal vez aparecieran en él algunas palabras más: asimismo, es seguro que dentro de medio siglo no quedará rastro de muchos vocablos que hoy figuran en él. Tal es el ritmo acelerado que se observa en la evolución del lenguaje de aquel valle, en otro tiempo recoleto y patriarcal, y en la actualidad abierto a toda clase de influencias extrañas, a pesar de que no han mejorado en un ápice sus comunicaciones con el exterior». 
de 2015 una iniciativa de recuperación de la toponimia y de la utilización tradicional de los recursos naturales, en el territorio de cada Junta Vecinal ${ }^{10}$.

Respecto a otro tipo de iniciativas habidas al respecto - académicas ${ }^{11}$, de instituciones privadas ${ }^{12} \mathrm{o}$ de estudiosos ${ }^{13}$ - se pretende en este caso dar un carácter sistemático al trabajo, tanto espacialmente - llegando a cubrir todos los términos concejiles - como en lo referido a la metodología empleada usando un esquema de proceso común que permita una homogeneización de los resultados y que incluya, como aspecto fundamental, la georreferenciación de la toponimia-.

Aparte del valor científico de los resultados esperables para la iniciativa, así como su contribución al mantenimiento de la identidad cultural de estos pueblos, el proyecto tiene la virtualidad de influir positivamente en la dinámica social, favoreciendo las relaciones intergeneracionales, el apego a la tierra de los jóvenes y de los emigrados y contribuyendo a romper la dinámica de falta de iniciativa sociocultural.

Así, el trabajo de recuperación puede suponer que, haciendo de la necesidad virtud, las limitaciones de las personas de edad provecta en la identificación en los recursos de geolocalización - bien sean analógicos o digitales- de parajes que han formado parte de su cotidianeidad, o en el manejo de tecnologías informáticas, den pie a la aparición de un espíritu de colaboración entre jóvenes o adultos y ancianos, potenciándose el aprecio y respeto mutuo a las capacidades de cada cual.

De otra parte, el conocimiento de las peculiaridades del territorio (toponimia, pautas de manejo ganadero tradicional) puede constituirse en un ingrediente fundamental en el empeño de que se creen «lazos de afecto hacia

10 Una iniciativa que forma parte del Catálogo abierto del patrimonio inmaterial de las Reservas de la Biosfera españolas (Fundación Fernando González Bernaldez, 2016: 164-165).

11 Tal es el caso de diversas memorias de licenciatura promovidas desde el ámbito universitario leonés, bien sea publicadas — p.e, Orallo (Llamazares, 1990)—o inéditas —p.e., Torrestío (Velado, 1985).

12 Podemos mencionar el Concurso de Recogida de Toponimia «Concha de Lama» del Club Xeitu, del cual han tenido lugar ya cuatro ediciones: su ámbito geográfico son los municipios de Villablino, Murias de Paredes, Riello, Valdesamario, Soto y Amío, Páramo del Sil, Palacios del Sil, San Emiliano, Cabrillanes, Sena de Luna y Barrios de Luna (provincia de León) y Pola de Somiedo, Cangas del Narcea y Degaña (Principado de Asturias). Asociado a tal concurso, el Club Xeitu ha puesto en marcha la publicación de la Serie Toponimia, con títulos referidos, hasta la fecha, a las localidades de La Majúa, La Vega de los Viejos, Montrondo (García, 2014), Rabanal de Abajo y Lumajo (en preparación, Sabugo).

13 Cabe destacar la labor de recopilación llevada a cabo por el agustino Fernando Rubio Álvarez y publicada a mediados del s. XX (Rubio, 1964). 
la tierra» (Riesco, 2010: 8) y de que las personas que no vivieron el sistema agrario tradicional sean «forasteras en su propio país» ${ }^{14}$.

Por último, estamos ante una actividad de participación de los colectivos locales de las que se vienen considerando necesarias para promover los estados de ánimo sociocomunitarios que se constituyen en vectores clave para el impulso del desarrollo endógeno.

Para ello, a lo largo de los meses de verano, pues es cuando hay más gente en los pueblos, pasando parte de sus vacaciones, se convoca a los vecinos de cada pueblo a un encuentro en el que se les plantea la conveniencia de proceder, mediante un trabajo voluntario y comunitario, a recuperar esa memoria, en el que los mayores aporten sus recuerdos y los jóvenes la capacidad de interpretar el territorio en documentos cartográficos, en la medida de las posibilidades que haya en cada núcleo.

Se les invita a recuperar todos los topónimos que puedan recordar, y a situarlos en unos mapas que se les entregan a propósito. Al tiempo se les propone que, mediante un ejercicio también memorístico, reconstruyan los recorridos que hacía cada tipo de ganado. Todo ello se sugiere a modo de actividad lúdica y a desarrollar de manera comunitaria y compartida, que sirva para que los mayores se sientan valorados en su papel de garantes de una memoria colectiva que atesora unos conocimientos importantes, y para que los más jóvenes aprendan una realidad cada vez más desconocida de la historia de la tierra de sus orígenes.

El método que se ha aplicado consta de las fases que se desarrollan a continuación.

\section{a) Preparación de la cartografía de base}

Se trata de una fase fundamental del trabajo, habida cuenta de que numerosas recopilaciones y trabajos toponímicos presentan, como carencia fundamental, la falta de geolocalización. En el caso de investigaciones de cierta antigüedad, se trata de una laguna que pudiera responder bien al paradigma dominante, en el ámbito de los estudios filológicos, respecto a la metodología a emplear en estos trabajos o bien a limitaciones técnicas ${ }^{15}$.

${ }^{14}$ Gaspar Melchor de Jovellanos, Discurso dirigido a la Real Sociedad de Amigos del País de Asturias sobre los medios de promover la felicidad de aquel Principado (Madrid, 22 de abril de 1781).

15 Por ejemplo, es poco probable que Guzmán Álvarez tuviera acceso a cartografía 1:50.000 para elaborar su conocida tesis doctoral El habla de Babia y Laciana (1947), que incluye una recopilación toponímica; las cuatro hojas del Mapa Topográfico Nacional de la zona fueron publicadas entre 1946 y 1951. 
A lo largo de los meses de junio y julio de 2015 se lleva a cabo un trabajo previo de recopilación de los documentos de base y preparación de la cartografía que luego se entregará en cada pueblo.

Los mapas base se obtienen de la página web del Instituto Geográfico Nacional, a través de su Centro de Descargas del CNIG (http://centrodedescargas.cnig. es/CentroDescargas/). Se utilizan en concreto las hojas del Mapa Topográfico Nacional E. 1:25.000.

El siguiente paso es saber cuál es el término de cada Junta Vecinal, es decir, cuál es su territorio administrativo concreto, y delimitarlo sobre el mapa topográfico, con el objetivo último de entregar en cada lugar no un mapa genérico, sino «el mapa de mi pueblo».

Esta es una información que no fue fácil de conseguir en nuestro caso, pues las Juntas Vecinales no tienen - no tenían hasta ese momento- mapas de su término. Sólo hay dos posibles soluciones para obtener esta información, que es fundamental:

- Una solución es que una persona con conocimientos técnicos de cartografía/topografía recorra el territorio de cada Junta Vecinal mapa en mano y, acompañado por una o más personas conocedoras de los lindes y mojones de su pueblo con los pueblos vecinos, deje constancia precisa de los mismos mediante el uso de un GPS. Se trata de un método costoso en tiempo, dinero y esfuerzo que suele tener la dificultad añadida de la imposibilidad de que los prácticos en la cuestión recorran las mojoneras, dada su avanzada edad y lo quebrado de los terrenos por los que estas suelen discurrir.

- Otra solución es conseguir la cartografía de los deslindes mediante el recurso a fuentes de información escrita o cartografías preexistentes:

- Deslindes antiguos: existen algunos deslindes antiguos en los archivos vecinales, si bien suele ser difícil su interpretación por los cambios habidos en la toponimia - especialmente en el caso de aquellos de fechas muy distantes en el tiempo ${ }^{16}$ -

- Actas y Cuadernos de Campo: se trata de una documentación textual y gráfica que obra en poder del Instituto Geográfico Nacional. Son deslindes de términos administrativos — realizados como paso previo a la elaboración del Mapa Topográfico Nacional y transpuestos posteriormente a las denominadas «pañoletas» de escala 1:25.000_, generalmente de municipios, aunque en algunas ocasiones también de términos anejos —no es el caso de los municipios de esta zona-.

\footnotetext{
16 En el caso de Montrondo, hay un deslinde del año 1643 (García, 2014: 91).
} 
- Inventarios de Bienes llevados a cabo bajo los auspicios del Servicio de Asistencia a Municipios de la Excma. Diputación Provincial de León, cuya fiabilidad depende del rigor aplicado por los consultores en la delimitación del término concejil.

- Información catastral: en ocasiones, los límites de términos anejos eran reflejados en la cartografía catastral, con lo cual pueden recuperarse, bien en soporte digital o bien consultando las fotografías aéreas retintadas depositadas en el Archivo Histórico Provincial. En cuanto al parcelario, no siempre se menciona la propiedad pública o el carácter de Monte de Utilidad Pública, no asociándose las parcelas privadas a una localidad concreta, sino al término municipal.

- Cartografía forestal: la cartografía de Montes de Utilidad Pública de la Junta de Castilla y León (14 en el caso de Murias de Paredes, uno por cada entidad local) puede servir para delimitar una parte del término anejo; son notables, no obstante, las disparidades del Catálogo de MUP's de la Provincia de León, en cuanto a la fiabilidad de los datos aportados.

En todo caso, podemos afirmar, como criterio general, que resulta más sencillo delimitar los términos concejiles en aquellas zonas que se corresponden con parcelas de propiedad comunal, mientras que los límites se diluyen en las zonas de propiedad privada. En ocasiones se identifica, de manera errónea, el término concejil con la vecindad de la mayoría de propietarios.

Una vez conocidos cuáles son los límites del término de cada pueblo, se traslada esa información a la cartografía 1:25.000, se individualiza el mapa de cada pueblo, y se imprimen varias copias en papel en tamaño suficientemente grande (DIN-A2 a DIN-A0, dependiendo de la extensión superficial de cada término).

En nuestro caso se imprimieron también a la misma escala los montajes de fotografía aérea vertical del Vuelo Americano Serie B, pues la imagen obtenida en este vuelo de 1957 recoge perfectamente la organización tradicional de estos territorios, diferenciándose las tierras en cultivo y en barbecho ese año, las zonas de prados, de huertas, de pastos, los caminos y veredas hoy perdidos, etcétera, informaciones muy útiles para ayudar a refrescar la memoria de los mayores y a situar en el mapa los topónimos.

B) Charlas de planteamiento de la iniciativa en cada pueblo

Una vez imprimidos los materiales cartográficos de base, se preparó una charla-modelo a desarrollar en cada pueblo. En nuestro caso se aprovechó la coyuntura del relanzamiento de la Reserva de la Biosfera, para llevar a cabo una labor de divulgación del significado de la Reserva, y relacionar este tema, que suele sonar bastante abstracto y lejano, con algo que fuese mucho más cercano 
y que tocase la fibra sensible de los vecinos: la recuperación de unos saberes tradicionales que estamos a punto de perder. Se comenzó por el Municipio de Murias de Paredes como laboratorio de experimentación.

A continuación, y de común acuerdo con los Presidentes de las Juntas Vecinales, se diseñó y acordó un calendario de charlas para que a lo largo de varios fines de semana del mes de agosto tuviese lugar un encuentro en cada uno de los quince pueblos del municipio.

Se prepararon unos carteles anunciadores del evento, al que se dio el título de El mapa de mi pueblo, que se distribuyeron a finales del mes de julio para que los Presidentes de las Juntas Vecinales los colocasen cuando considerasen oportuno, en función de la fecha en la que fuese a tener lugar la charla en cada pueblo. Se insistió también en la conveniencia de hacer una difusión del anuncio mediante el boca a boca.

Las charlas fueron impartidas por el concejal de medio ambiente y desarrollo rural, y en ellas, tras el planteamiento genérico del problema, se invitaba a los vecinos a ponerse manos a la obra, y juntos chicos y grandes, nietos y abuelos, y aprovechando los días de vacaciones, implicarse en esta labor colectiva. Se les presentaban los materiales a utilizar para ello — los mapas-y se daba por abierto un plazo indefinido para llevar a cabo el trabajo.

La asistencia a las charlas fue muy desigual, dependiendo de la mayor o menor población veraneante en cada pueblo, de la mayor o menor cohesión social que hay en cada uno, de la implicación del Presidente y demás integrantes de la Junta Vecinal en la labor previa de aviso y preparación del evento, etcétera.

La respuesta en todos los casos fue muy positiva, valorándose por todos los adultos como algo necesario y conveniente la iniciativa de recuperar esa memoria común del uso de su territorio.

C) Seguimiento del desarrollo de los trabajos

A lo largo de los meses siguientes se fueron desarrollando en cada pueblo las tareas propuestas, con distintos ritmos y de diferentes maneras dependiendo de las personas que asumiesen el liderazgo de la iniciativa. La clave ha estado en este aspecto último: la existencia de un vecino en cada pueblo que se implique directamente en llevar a cabo el trabajo y anime y coordine a otros vecinos en ello.

En algunos pueblos ya había alguien que había iniciado un trabajo similar de recuperación de la toponimia, y que vio facilitada su labor con los medios cartográficos facilitados. En algún caso incluso ya se había llevado a cabo (García, 2014).

En aquellos lugares donde había alguna persona más o menos joven con conocimientos o capacidad para trabajar con documentos cartográficos en la 
pantalla del ordenador los trabajos avanzaron a buen ritmo, combinando la recogida de los topónimos, su localización en el mapa, y la comprobación posterior en campo, para corroborar la localización de cada topónimo lo más exacta posible.

En algunos pueblos la iniciativa quedó congelada, y fue necesario darle un nuevo impulso, a lo que contribuye decisivamente la divulgación de que en los pueblos próximos ya se está avanzando en el tema, o ya se ha hecho, y se facilita copia de los resultados en borrador, pues eso es un acicate importante.

D) RECOGIDA DE LOS RESULTADOS, ANÁLISIS Y SISTEMATIZACIÓN DE LOS MISMOS

Los resultados se recogen en la concejalía en los diversos formatos en los que van siendo entregados por los vecinos que se han encargado o por los presidentes de las Juntas Vecinales: formatos GIS, formatos gráficos no georrreferenciados realizados mediante programas de dibujo sencillos, hasta incluso apuntes a mano sobre los mapas originales en papel que se facilitaron en su momento.

A partir de ahí se realiza una triple tarea:

- Por un lado, la sistematización de los materiales elaborados, pasándolos todos a un formato homogéneo que facilite su impresión y posterior difusión y exposición.

- De otro, el análisis y elaboración de los datos obtenidos, especialmente en lo que se refiere a la memoria ganadera del territorio: recorridos de los distintos tipos de ganado, lugares de sesteo, abrevaderos, pastaderos, vados, fechas de aprovechamiento de unas u otras zonas, etcétera, cartografiando en la medida de lo posible esos datos, para que puedan ser también expuestos posteriormente en mapas de formato mural.

- Finalmente, se llegó a un acuerdo con el Servicio de Cartografía Básica del Instituto Geográfico Nacional, al que se fueron enviando los originales recibidos en lo que se refiere a la toponimia. En el IGN se revisó la información y se incluyó aquella apropiada para la escala 1:25.000 (teniendo en cuenta las pautas de normalización preestablecidas). Se corrigieron topónimos erróneos en cuanto a su transcripción o localización. El resto de información queda registrada en un sistema de gestión de incidencias para que se introduzca en la Base Topográfica Numérica BTN25. El IGN hizo saber al Ayuntamiento de Murias de Paredes su alta consideración de la labor realizada y la importancia de la información recibida.

E) DeVolución de los materiales elaborados y divUlgación de LA EXPERIENCIA

El último paso consiste en devolver los resultados a la población protagonista del proceso: los vecinos de los pueblos. Para ello se imprime, de cada pueblo, un mapa a tamaño DIN-A0 con toda la toponimia. Se programan charlas para 
el siguiente verano en las que se explican los resultados obtenidos y se hace una entrega oficial de los mapas resultantes.

En la cabecera municipal se lleva a cabo una exposición con algunos de los mapas más vistosos, en la que se expone la experiencia y sus resultados, que queda visitable y abierta al público en general.

\section{RESULTADOS OBTENIDOS}

A principios de 2017 se ha recopilado y cartografiado la toponimia de la mayor parte del municipio de Murias de Paredes, habiéndose completado la labor en las pedanías de: Fasgar, Lazado, Los Bayos, Montrondo, Murias de Paredes, Sabugo, Torrecillo, Vegapujín, Villabandín y Villanueva; es decir, de 10 de las 15 que lo forman. En el municipio de Los Barrios de Luna: Mallo de Luna. En el municipio de Riello: Ariego de Abajo y de Arriba. En el municipio de Sena de Luna: Sena de Luna. En el municipio de Soto y Amío: Carrizal y Santovenia de San Marcos. En el municipio de Valdesamario: Valdesamario, La Garandilla y Ponjos.

Una primera parte de esa información — la referida a la pedanía de Vegapujín - ha sido remitida al Servicio de Cartografía Básica, del Área de Cartografía, de la Subdirección General de Geodesia y Cartografía, del Instituto Geográfico Nacional habiéndose incorporado ya al visor del 1:25.000 del Iberpix una selección de los topónimos recopilados, tal como se expresa en las figuras 2 a 4 . A través de estas figuras pretendemos ilustrar de manera gráfica cuáles son los resultados obtenidos. En la figura 2 se puede apreciar cómo aparecían recogidos los topónimos de los alrededores de la localidad de Vegapujín en el 1:25.000.

En la figura 3 se representa ese mismo espacio en el borrador que se utilizó para recopilar toda la toponimia. Estimamos que se han recogido más del 90\% de los topónimos. Obviamente, a esa escala es imposible representarlos todos. La toponimia completa exigiría una cartografía de escala 1:10.000 o 1:5.000.

En la figura 4 se recoge esa misma zona tal como aparece actualmente en el visor del Iberpix. Como se puede apreciar, el IGN ha llevado a cabo una labor de selección de toda la información toponímica suministrada, para publicar sólo aquellos topónimos que permite la norma a la escala 1:25.000. Lo significativo es que se han añadido nuevos topónimos, se han corregido otros, y se han recolocado otros que no estaban bien situados. El patrimonio toponímico ha quedado de esta manera correctamente recogido, y garantizada su custodia y su difusión, que en el futuro es previsible que abarque a la totalidad de los topónimos, cuando haya disponible una cartografía de escala más detallada. 
FIGURA 2

RECORTE DEL 1:25.000 DE LA LOCALIDAD DE VEGAPUJÍN (MURIAS DE PAREDES, LEÓN) TAL COMO APARECÍA EN EL VISOR DEL IBERPIX ANTES DE LA RECOPILACIÓN TOPONÍMICA

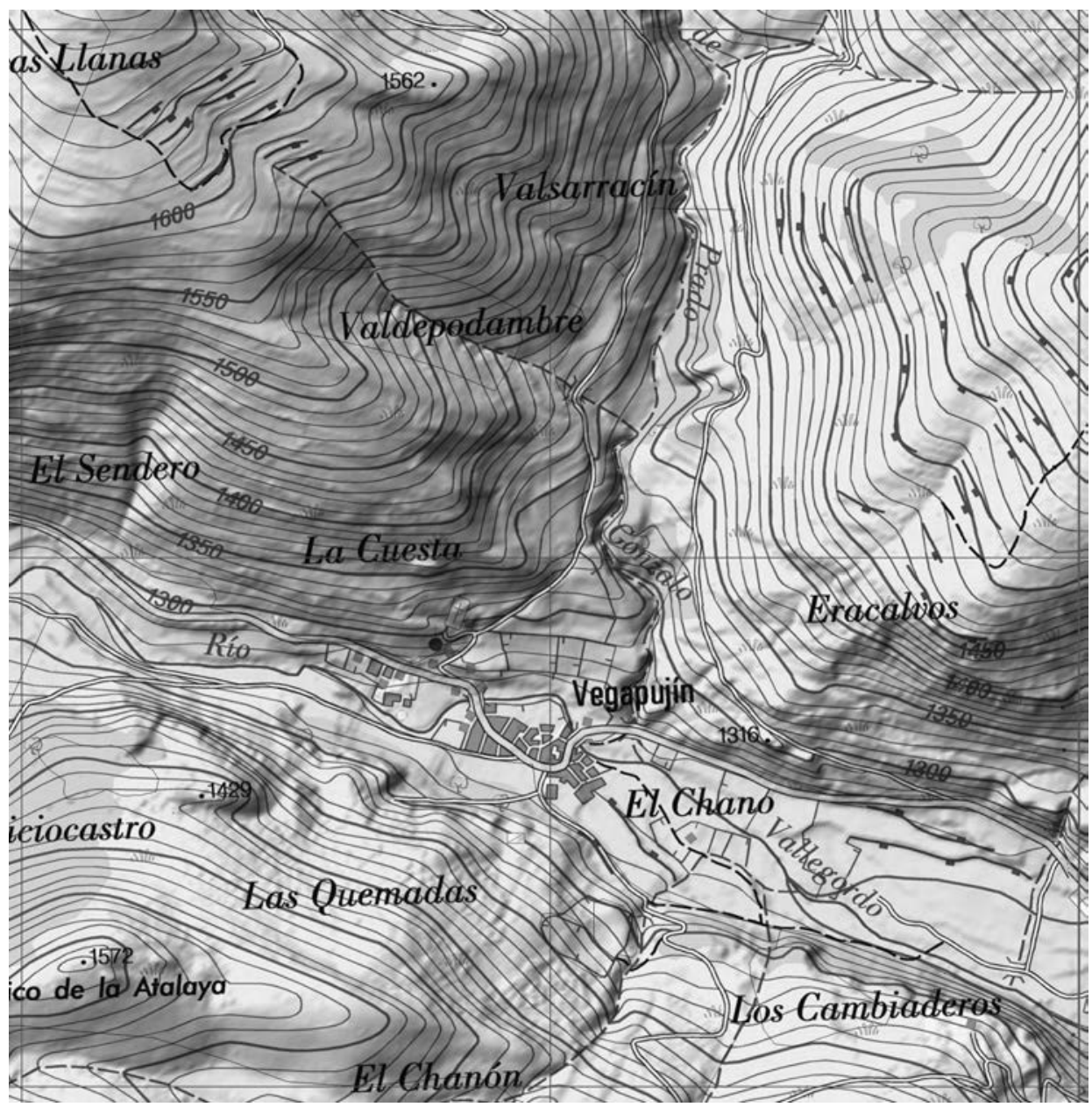

Estudios Geográficos, Vol. LXXIX, 284, pp. 191-208, enero-junio 2018

ISSN: 0014-1496, eISSN: 1988-8546, doi: https//doi.org/10.3989/estgeogr.201808 
FIGURA 3

RECORTE DEL MAPA DE TRABAJO PARA LA RECOPILACIÓN TOPONÍMICA. APARECEN TODOS LOS TOPÓNIMOS RECOGIDOS EN LA MISMA ZONA DE LA FIGURA 2

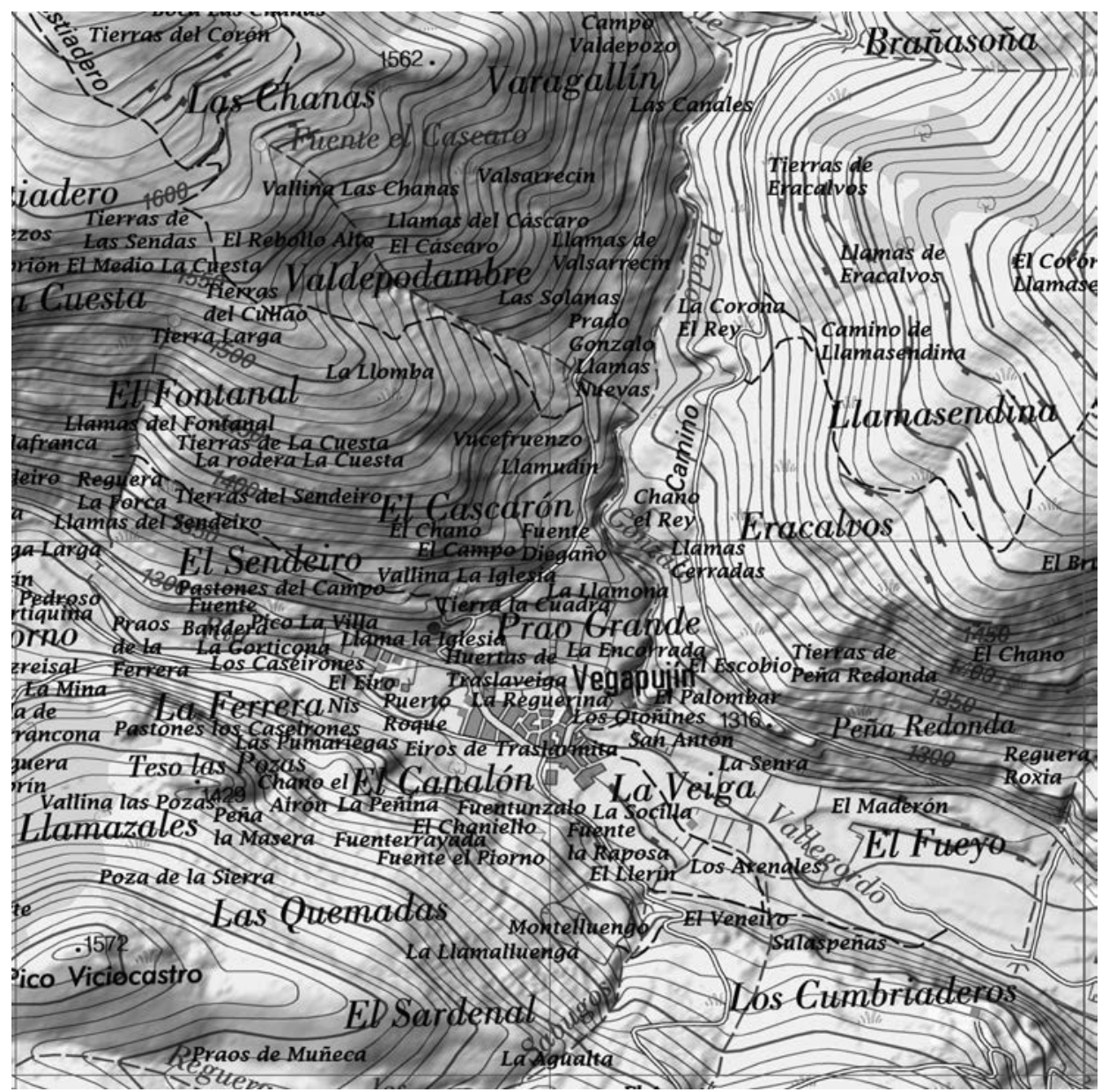


FIGURA 4

RESULTADO FINAL EN EL VISOR DEL IBERPIX, TAL COMO APARECE EN LA ACTUALIDAD

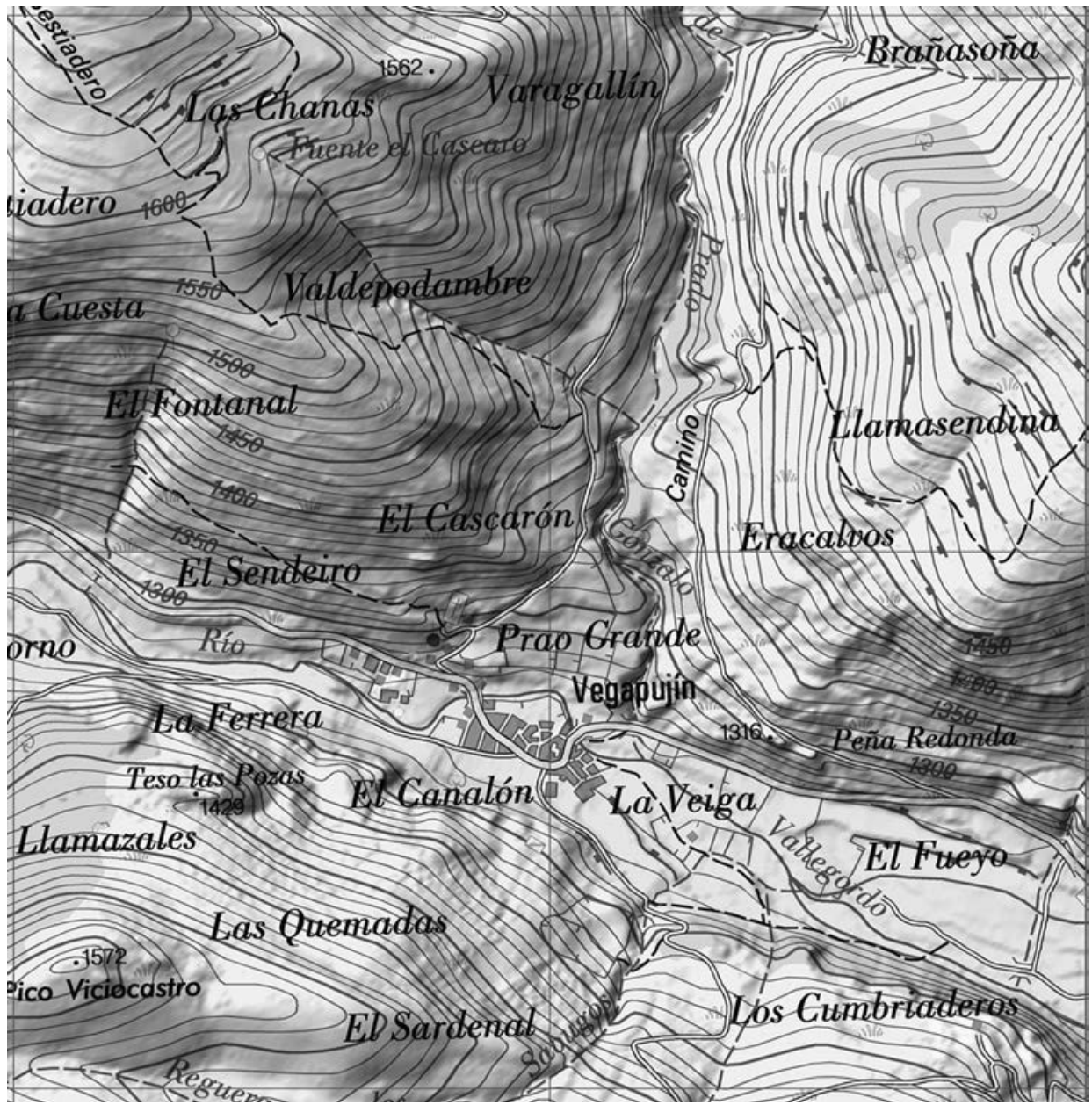

En definitiva, podemos destacar como resultado primero, y más importante, que se está consiguiendo la preservación de una parte muy significativa del acervo cultural del territorio de la Reserva de la Biosfera, como es la toponimia, pero con la particularidad de que se está consiguiendo la preservación de la toponimia localizada en el mapa, georreferenciada, no meros listados de topónimos. 
En segundo lugar, esa recopilación se está trasladando a una plataforma homogeneizadora y de difusión general, como es el Instituto Geográfico Nacional, por lo que estará disponible para todo tipo de investigadores e interesados.

\section{DISCUSIÓN}

La experiencia ha contribuido a revalorizar aspectos de la cultura local que se daban por perdidos, por irrecuperables o por inútiles, dándoles un carácter de patrimonio cultural inmaterial que puede tener, en el futuro, nuevas utilidades (ligadas por ejemplo a la investigación filológica, arqueológica, ambiental, etc.). Todo ello, realizado por los propios habitantes, ha generado también interesantes dinámicas intergeneracionales.

Se está utilizando la experiencia para comenzar a recuperar otros saberes tradicionales ligados al territorio y a su uso y aprovechamiento: pagos de cultivo, usos ganaderos, forestales, etc.

Hemos constatado un efecto demostrativo para otras localidades, en especial núcleos de las Reservas de la Biosfera colindantes, interesados en replicar la experiencia.

\section{BiBLIOGRAFÍA}

Arroyo Ilera, F. (2010): "Creciente interés geográfico por la toponimia", Estudios Geográficos, núm. 268, pp. 299-309.

Cortizo Álvarez, J., García de Celis, A., López Trigal, L. y Maya Frades, A. (1994): La Omaña. Transformaciones en un espacio rural de la montaña leonesa, León, Universidad de León, 125 pp.

Fundación Fernando González Bernaldez (2016): Catálogo abierto del patrimonio inmaterial de las Reservas de la Biosfera españolas, Madrid, Organismo Autónomo Parques Nacionales y Ministerio de Agricultura, Alimentación y Medio Ambiente, $243 \mathrm{pp}$.

Gancedo Fernández, M. (2013): Tseite, tsinu, tsume, tsana. El habla de Laciana. Tomo I. "Castellano-Patsuezu", León, Piélago del Moro Ediciones, 2.156 pp.

García Martínez, A. (2014): Toponimia de Montrondo, León, Asociación Club Xeitu de la Montaña Occidental Astur-Leonesa, $140 \mathrm{pp}$.

Gordón Peral, Ma.D. (2011): "La memoria de los lugares: la toponimia", Revista PH, núm. 77 , pp. 90-91.

Le Men Moyer, J. (1996): Repertorio de Léxico Leonés, León, Universidad de León, $2.182 \mathrm{pp}$. 
Llamazares Prieto, M. T. (1990): Toponimia de Orallo, León, Diputación Provincial de León e Institución Fray Bernardo de Sahagún, 139 pp.

Pérez Álvarez, Ma . J. (1994): "El régimen concejil de Omaña, inspector de toda la actividad local”, Tierras de León, núms. 95-96, pp. 82-102.

Pérez Álvarez, M‥ J. (1998): Omaña y sus concejos en el siglo XVIII, León, Universidad de León, 174 pp.

Prada Llorente, E. (2004): El paisaje como archivo del territorio, Madrid, Instituto Juan de Herrera, $66 \mathrm{pp}$.

Prada Llorente, E., Riesco Chueca, P. y Herrero Tejedor, T. (2013): "Paisaje e imagen: formas y herencias en la construcción cultural del territorio agrario", Estudios Geográficos, núm. 275, pp. 557-583.

Riesco Chueca, P. (2010): "Nombres de paisaje: la toponimia, fuente de conocimiento y aprecio del territorio", Cuadernos Geográficos de la Universidad de Granada, núm. 46, pp. 7-34.

Rosselló i Verger, V.M. (2010): Toponímia, geografia i cartografia, Valéncia, Universitat de València, 403 pp.

Rubio Álvarez, F. (1956): "Vocabulario dialectal del Valle Gordo (León)", Revista de Dialectología y Tradiciones Populares, núm. XII, pp. 235-257.

Rubio Álvarez, F. (1958): "Algunas manifestaciones folklóricas del Valle Gordo (León)”, Revista de Dialectología y Tradiciones Populares, núm. XIV, pp. 354-370.

Rubio Álvarez, F. (1961): "Vocabulario dialectal del Valle Gordo (León)", Revista de Dialectología y Tradiciones Populares, núm. XVII, pp. 264-320.

Rubio Álvarez, F. (1964): "Toponimia menor del Valle Gordo (León)", Revista de Dialectología y Tradiciones Populares, núm. XX, pp. 77-89.

Rubio Pérez, L.M. (1993): El sistema político concejil en la provincia de León, León, Universidad de León, 472 pp.

Tort i Donada, J. (2001): "La toponímia com a camp de coneixement interdisciplinari. Algunes bases teòriques i epistemològiques per a l' estudi del noms de lloc", Scripta Nova, núm. 86, 29 pp.

Tort i Donada, J. (2003): "Toponimia y marginalidad geográfica. Los nombres de lugar como reflejo de una interpretación del espacio", Scripta Nova, núm. 138, 9 pp.

Tort i Donada, J. (2010): "A propòsit de la dimensió espacial dels noms de lloc. Algunes reflexions teòriques", Treballs de la Societat Catalana de Geografia, núm. 70, pp. 55-76.

Tort i Donada, J. (2012): "Espai y temps en toponímia. Una aproximació de la geografia”, en Actes del XXXIII Col-loqui de la Societat d' Onomàstica, Tarragona, Centre d' Estudis de la Conca de Barberà y Societat d' Onomàstica, pp. 277-287.

Velado Herreras, M. (1985): El léxico de Torrestío, León, Universidad de León, Tesis de Licenciatura (inédita).

Fecha de recepción: 12 de septiembre de 2017.

Fecha de aceptación: 21 de febrero de 2018. 